\title{
Intraosseous Schwannoma of the Left Infra Temporal Region Involving Oral Cavity: A Case Report
}

\author{
*Dr. Arun Subramaniam, **Dr. Tulsi Subramaniam, ***Dr. Digamber Sable, \\ ****Dr. Asha Chowdhery, *****Dr. Pallavi Channe, ******Dr Abhignini Gavarraju \\ *Professor \& Head, Dept. of Oral Medicine \& Radiology, Dr.D.Y.Patil Dental College \& Hospital, DPU, Pune, \\ Maharashtra \\ **Professor, Dept. of Prosthodontics \& Crown \& Bridge, Dr.D.Y.Patil Dental College \& Hospital, DPU, Pune, \\ Maharashtra \\ ***Professor, Dept. of Oral Medicine \& Radiology, Dr.D.Y.Patil Dental College \& Hospital, DPU, Pune, \\ Maharashtra \\ ****Professor, Dept. of Oral Medicine \& Radiology, Dr.D.Y.Patil Dental College \& Hospital, DPU, Pune, \\ Maharashtra \\ *****Senior Lecturer, Dept. of Oral Medicine \& Radiology, Dr.D.Y.Patil Dental College \& Hospital, DPU, \\ Pune, Maharashtra \\ ****** PG student, Oral Medicine \& Radiology, Dr.D.Y.Patil Dental College \& Hospital, DPU, Pune, \\ Maharashtra
}

\begin{abstract}
A 33-year-old male patient was referred to the OPD with the chief complaint of pain and swelling in the posterior part of the upper jaw region. A screening Panoramic radiography disclosed no frank changes. A complete excision was achieved by removing the tumor. Histologically, Antoni-A tissue was the predominant microscopic pattern, but it occasionally alternated with Antoni-B areas. Immunohistochemical staining for $S$ 100 proteins showed diffusely positive findings. An examination confirmed a diagnosis of an intraosseous schwannoma of the maxilla.
\end{abstract}

Key words: schwannoma, infra temporal region

\section{Introduction}

Schwannoma is a benign tumor from Schwann cells of the neural sheath ${ }^{1}$. Although the occurrence of schwannomas in the head and neck area is relatively high, an intra osseous schwannoma is rare, presenting in less than $1 \%$ of benign primary bone tumors ${ }^{2,3}$. We herein report a rare case of an intra osseous schwannoma of the left infra temporal region involving oral cavity.

\section{Case Report}

A 33-year-old male patient with pain and swelling in the left maxillary region (Fig 1)was referred to the OPD department. His dental history indicated that he had a similar complaint 2 months ago with the presence of a swelling and a lesion which he got excised at that time. Patient has subsequently observed a recurrence of lesion with gradual increase in the size of lesion to the present size and pain since 1 month.

A clinical examination revealed extra oral swelling extending from corner of the mouth to anterior border of the ramus of the mandible anterioposteriorly; and superioinferiorly from inferior orbital rim to lower border of the mandible (Fig. 1). Intra orally a growth extending from left first molar to retromolar area of size approximately $3 \mathrm{~cm}$ by $2 \mathrm{~cm}$ was seen (Fig. 2). A neurosensory examination was normal. Panoramic radiography revealed nothing abnormal. There were no apparent signs of resorption or displacement of the roots of the left maxillary arch (Fig. 3). MRI images confirmed a well-defined osteolytic lesion of the left infra temporal region involving oral cavity (Fig. 4 and 5).

We suggested that the cause of the pain and swelling was recurrence of schwannoma. 


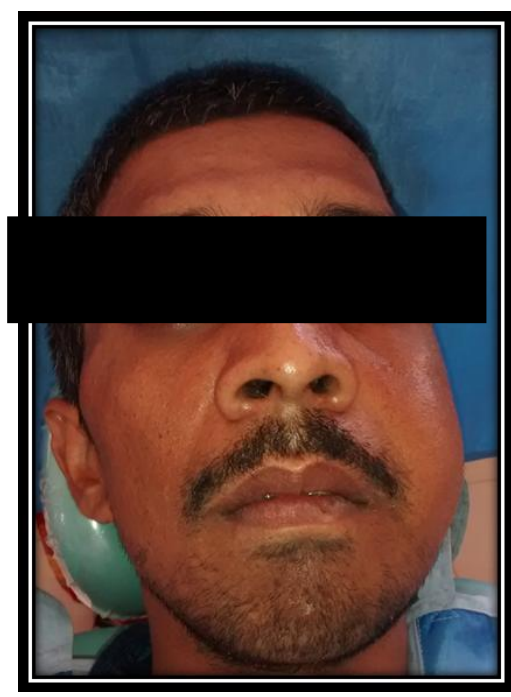

Fig. 1 Swelling in upper left molar region

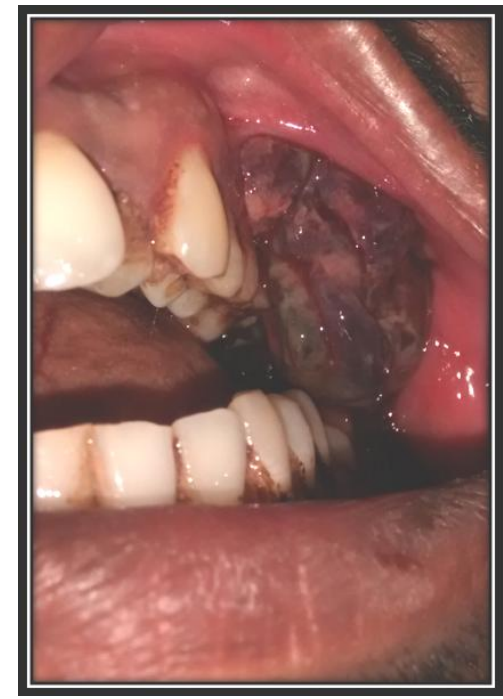

Fig.2: A $3 \mathrm{~cm} \times 2 \mathrm{~cm}$ intra oral growth

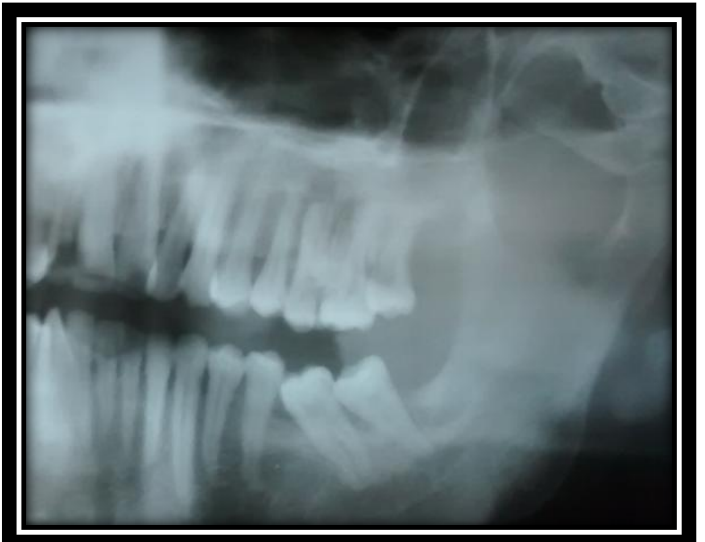

Fig. 3. Panoramic radiography showing no changes
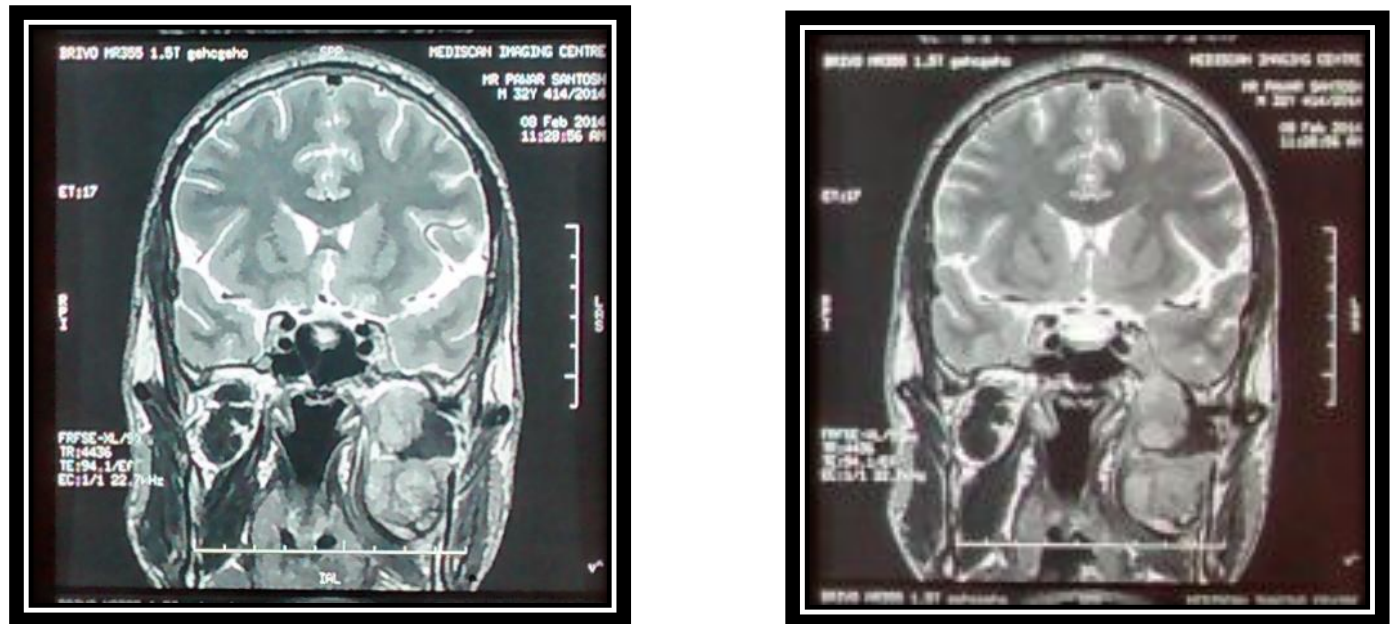

Fig. 4 and 5. An MRI scan showing a space-occupying mass with clear borders. .

Immunohistochemical staining for S-100 proteins showed diffusely positive findings . The diagnosis was an intraosseous schwannoma arising from the left infra temporal region extending into the oral cavity .

Histopathological report suggested that it shows a benign spindle cell tumour composed predominantly Antoni type A areas, which are cellular and are composed of spindle cells arranged in a palisading fasion and at places, in an organoid arrangement, tumour showed low mitotic activity. (Fig 5 and 6) The final diagnosis was given as LEFT MECKEL'S CAVE SCHWANNOMA. 

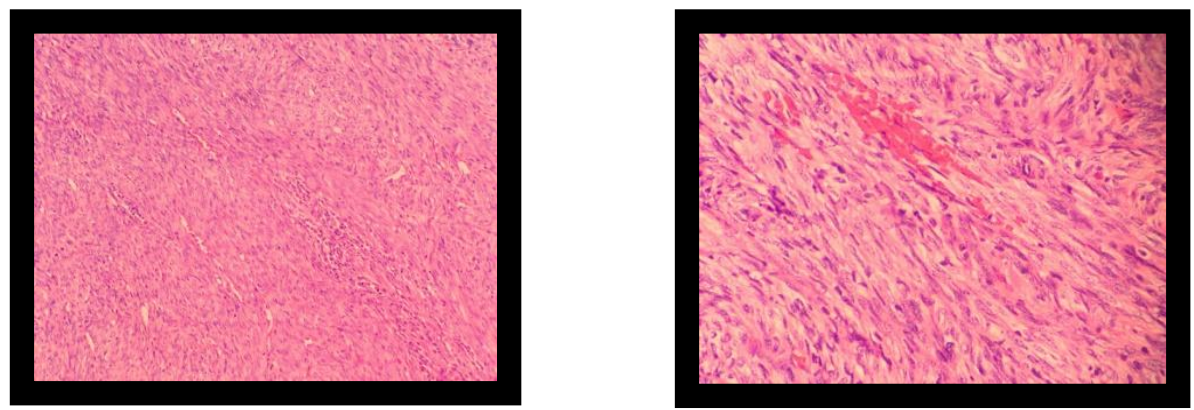

Fig 5 and 6 : Spindle cell hypercellular areas noted (Antoni A) with cells arranged in bundles and fascicles. Tumor cells showing nuclear hyperchromasia

\section{Discussion}

Schwannoma (neurinoma, neurilemmoma) is a benign tumor arising from the peripheral neural sheath. Although the head and neck region is one of the most common sites for benign nerve-sheath tumors, intraoral lesions are unusual, particularly in the intraosseous region of the jaw. There is a female predilection, with a 1.5:1 female-to-male ratio ${ }^{2}$. The average age is 34 years, with a peak prevalence in the second and third decades of life ${ }^{4}$

Clinically, schwannoma is a slow-growing tumor that may be present for years before becoming symptomatic $^{5}$. Swelling is the most common symptom, but pain or paresthesia may also be present in approximately $50 \%$ of such cases ${ }^{6}$.

The usual radiographic appearance is of a well-defined unilocular nonspecific radiolucent lesion, with root divergence (expansive growth) and root resorption only in teeth contacting the lesion ${ }^{7}$. The possibility of an intraosseous schwannoma was not considered at first because of the extreme rarity of this location. Differential diagnosis of fibroma, fibrolipoma, neurofibroma, schwannoma, fibromyxoma or leiomyoma was considered ${ }^{8}$. The histopathological examination provided a definitive diagnosis for this case.

Histologically, there are two types of tissue arrangement: Antoni-A and B. Alternation between Antoni-A and B regions is common. Antoni-A type is composed of aligned fusiform cells, forming a typical palisade. Between the fibrils there are small eosinophilic masses called Verocay bodies ${ }^{9}$.

Antoni-B type is composed of a smaller number of cells and the spindle cells are randomly arranged within a loose myxomatousstroma . In the present case, Antoni-A type was the predominant microscopic pattern. However, no typical Verocay bodies were identified .

A surgical excision is the treatment of choice and every effort should be made to preserve the integrity of the facial structures ${ }^{10}$. In this case, however, the tumor presented with an appearance making preservation or even an complete excision became impossible. However, a complete excision has a good prognosis due to the low recurrence rate and the rarity of malignant transformation

\section{References}

[1]. BaniA, Gilsbach JM: Incidence of cerebrospinal fluid leak after microsurgical removal of vestibular schwannomas. ActaNeurochir (Wien) 144:979- 982; discussion 982, 2002

[2]. JadvygaS .An early diagnosis of spinal cord schwannoma: the value of the pain syndrome MEDICINA (2002) Vol. 38, No. 11, 1086-8

[3]. Avani Gandhi Dikshit, Arun Subramaniam, A rare intra-osseous Schwannoma- A diagnostic challenge. Indian Journal of Dentistry, Vol 2, Issue 4, Oct-Dec 2011, 165-171

[4]. Kurtkaya-Y,Scheithauer.B, and Woodruff.J.Y. The pathobiology spectrum of Schwannomas. HistolHistopathol (2003) 18: 925934

[5]. Gharabaghi, A.; Samii, A.; Koerbel, A.; Rosahl, S. K.; Tatagiba, M. \& Samii, M. (2007), 'Preservation of function in vestibular schwannoma surgery. Neurosurgery 60(2 Suppl 1), ONS124 - 7; discussion ONS127-8.

[6]. Colreavy MP, Lacy PD, Hughes J, Bouchier-Hayes D, Brennan P, O'Dwyer AJ, et al. Head and neck schwannomas-a 10 year review. J Laryngol Otol 2000;114:119-24.

[7]. Maria L, Asier E, Rafael M, Juan C, José M. Ancient Schwannoma of the hard palate. An uncommon case report and review. J ClinExp Dent. 2013;5(1): 62-5.

[8]. Wanjari SP, Wanjari PV, Parwnai RN, Tekade SA, Case report: Unusually large quiescent ancient schwannoma of hypoglossal nerve. Indian Journal of Dental Research, 2013;24(6), 768-71

[9]. Joseph P, Mumtaz V R, Amyn M R. Vascular alterations in schwannoma. Int J ClinExpPathol 2014; 7(7):4032-4038.

[10]. Chen CY, Wang WC, Chen CH, Chen YK, Lin LM Ancient schwannoma of the mouth floor -a case report and review. Oral Oncol 2006;42:281-5.

[11]. Disclosure regarding conflict of interest and source of funding: The authors wish to state that there is no conflict of interest. There is no external source of funding, all expenses related to the article have been entirely borne by the corresponding author

[12]. Corresponding author: Dr. Arun Subramaniam MDS, e-mail: arunsubramaniam66@gmail.com 